\title{
Study of Plume Impingement Effects in the Lunar Lander Environment
}

\author{
J. Marichalar*, A. Prisbell*, F. Lumpkin ${ }^{\dagger}$, G. LeBeau ${ }^{\dagger}$ \\ *Jacobs Technology, Houston, TX 77058, USA \\ ${ }^{\dagger}$ NASA Johnson Space Center, Houston, TX 77058, USA
}

\begin{abstract}
Plume impingement effects from the descent and ascent engine firings of the Lunar Lander were analyzed in support of the Lunar Architecture Team under the Constellation Program. The descent stage analysis was performed to obtain shear and pressure forces on the lunar surface as well as velocity and density profiles in the flow field in an effort to understand lunar soil erosion and ejected soil impact damage which was analyzed as part of a separate study. A Computational Fluid Dynamics (CFD)/Direct Simulation Monte Carlo (DSMC) decoupled methodology was used with the Bird continuum breakdown parameter to distinguish the continuum flow from the rarefied flow. The ascent stage analysis was performed to ascertain the forces and moments acting on the Lunar Lander Ascent Module due to the firing of the main engine on take-off. The Reacting and Multiphase Program (RAMP) method of characteristics (MOC) code was used to model the continuum region of the nozzle plume, and the DSMC Analysis Code (DAC) was used to model the impingement results in the rarefied region. The ascent module (AM) was analyzed for various pitch and yaw rotations and for various heights in relation to the descent module (DM). For the ascent stage analysis, the plume inflow boundary was located near the nozzle exit plane in a region where the flow number density was large enough to make the DSMC solution computationally expensive. Therefore, a scaling coefficient was used to make the DSMC solution more computationally manageable. An analysis of the effects of this scaling technique was performed. Because the inflow boundary was near the nozzle exit plane, another analysis was performed investigating three different inflow contours to determine the effects of the flow expansion around the nozzle lip on the final plume impingement results.
\end{abstract}

Keywords: DSMC, Plume Impingement, Rarefied Flow

PACS: 05,51

\section{INTRODUCTION}

During the Constellation Program, one of the main objectives for the NASA Vision for Space Exploration was to return humans to the moon and establish a lunar outpost. Similar to the Apollo landings, the Constellation Lander, Altair, was conceived to descend to and ascend from the surface of the moon using variable thrust rocket engines and include separate descent and ascent stages. Because an established outpost is the goal and raw materials are limited, recycling and re-using the components of the spent descent stage is desirable. It is also highly desirable to have the descent stage landing zone within a reasonable distance of the outpost.

The plume from the descent stage firing will impinge upon the lunar surface causing large amounts of soil erosion effectively "sand blasting" any equipment in the surrounding landing zone with lunar dust (see Figure 1). In the current design, the ascent stage engine will be embedded inside the descent stage, and the nozzle exit plane will be in very close proximity to many descent stage components including spent fuel tanks. In this configuration, the descent stage components will come in direct contact with the core of the plume and receive an extreme amount of heating for a short duration. In addition, the reflection of the plume exhaust forces from the descent stage will affect the launch of the ascent vehicle. Understanding the plume impingement effects of the descent and ascent stage thruster firings on the surrounding environments is necessary to quantify the possible risk of damage to an established lunar outpost and any re-usable descent stage components as well as the forces acting on the ascent vehicle during launch.

High speed continuum gas flow emanating from a rocket nozzle and dissipating to rarefied gas into the vacuum of space is an intriguing and difficult problem for typical flow field analyses, especially those involving either 
computational fluid dynamics (CFD) or direct simulation Monte Carlo (DSMC) techniques. It is a problem that has been studied in numerous investigations [1-3]. Indeed, the problem of plume impingement in the lunar environment during the Apollo moon landings was extensively studied using various methodologies [4-8].

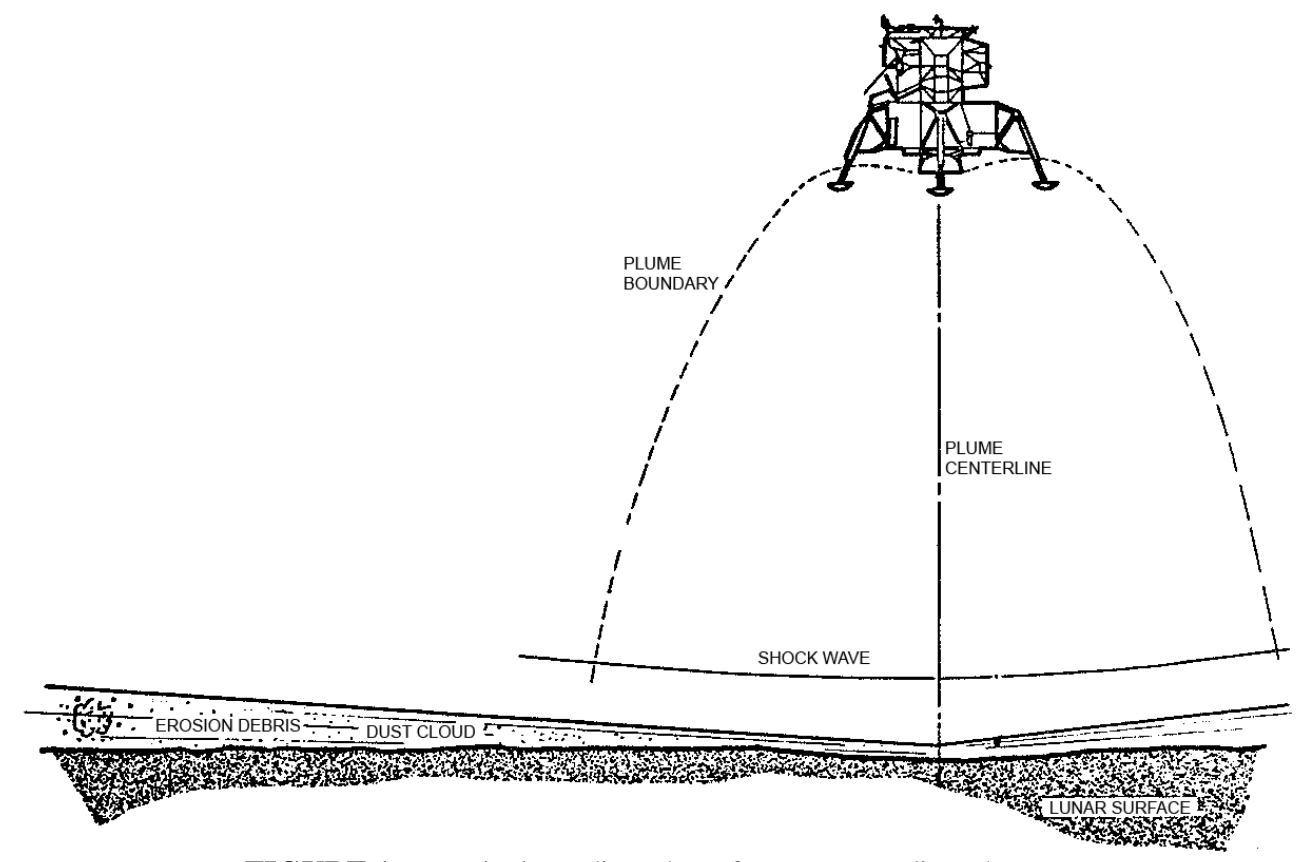

FIGURE 1. Terminal Landing Phase for Lunar Landing [4].

\section{PURPOSE}

The purpose of this study was to perform an analysis of the plume impingement effects for Apollo-type descent and ascent stage engine firings with the current Altair geometry employing some of the latest advanced simulation tools and techniques. The first objective was to obtain high resolution plume flow field characteristics for the descent stage engine firing for the purpose of tracking the lunar soil debris cloud. The second objective was to obtain pressure forces and moments on the ascent stage vehicle due to plume interaction with the descent stage, as well as plume heating environments on the surface of the descent stage components in close proximity to the ascent stage engine plume.

\section{METHODOLOGY AND ASSUMPTIONS}

Different methods were used to analyze the descent and ascent stage engine firings. These methods were selected based on the availability of engine data, time constraints and the measure of accuracy needed.

For the descent stage analysis, a decoupled hybrid CFD/DSMC method was used based on the procedure described in Reference [9]. An existing axisymmetric CFD simulation of the Apollo descent stage engine, previously performed with the General Aerodynamic Simulation Program (GASP) [10], was used to develop the inflow to the DSMC simulation. The CFD simulation included both the nozzle and plume flow fields. The inflow surface developed for the DSMC solution was based on the recommended Bird breakdown parameter [11] of 0.05. This methodology was deemed acceptable for cases where the boundary of the inflow was a significant distance from the lunar surface and the impingement shock. This "safe" distance corresponded to a nozzle exit plane altitude of approximately $15-20$ nozzle radii, $\mathrm{R}_{\mathrm{n}}$.

For the ascent stage analysis, a different decoupled hybrid method was used based on the Reacting Multiphase (RAMP) method-of-characteristics (MOC) code [12]. Although both the nozzle and plume for the ascent engine were simulated, the inflow boundary to the DSMC simulation was placed very close to the nozzle exit plane due to the geometric constraint for the lowest nozzle height at time of launch. The RAMP code was used for the ascent simulation instead of CFD for the following reasons: (1) the Altair design for the ascent module (including engine type and placement) is in continual flux; (2) the RAMP code allowed for rapid simulation of the ascent engine flow 
field; and (3) the results of the analysis would be used more for qualitative purposes than quantitative. Because the plume inflow boundary was located in a region where the flow number density was large enough to make the DSMC solution computationally expensive, a scaling coefficient was used to make the DSMC solution more manageable. An analysis of the effects of this scaling technique on the final results was performed. Another analysis was performed investigating three different inflow contour shapes to determine the effects of the flow expansion around the nozzle lip on the final results.

All DSMC simulations were performed with the NASA Johnson Space Center DSMC Analysis Code (DAC) [13]. The DAC option for nearest neighbor collisions was used for all simulations as described in Reference [14], which allows for relaxation of the standard 1.0 ratio of mean-free-path-to-cell-size resolution.

\section{Assumptions for Descent Stage Analysis}

The CFD simulation of the descent engine was performed with the GASP code as part of a separate study. The engine was modeled based on the Apollo Lunar Module Descent Engine (LMDE) as a liquid bipropellant engine with hypergolic ignition. The engine was assumed to have a 100\% thrust level of $3000 \mathrm{lbf}$, which is about $30 \%$ of the maximum thrust achievable with the Apollo LMDE. DSMC solutions were computed with various grids for the lunar surface incorporating a large spectrum of crater sizes, depths and distance from the plume centerline. DSMC simulations were performed for different altitudes, thrust levels and nozzle attitude angles. The parameters for the entire solution set are listed in Table 1.

TABLE (1). Parameters Varied for Descent Stage Analysis.

\begin{tabular}{lcccc}
\hline Crater Radius & Crater Type & Nozzle Attitude & Nozzle Altitude & $\begin{array}{c}\text { Thrust } \\
\text { (\%) 3000 lbf) }\end{array}$ \\
\hline $1 \mathrm{R}_{\mathrm{n}}$ & Toroid & $32.5^{\circ}$ & $20 \mathrm{R}_{\mathrm{n}}$ & $100 \%$ \\
$1 \mathrm{R}_{\mathrm{n}}$ & Toroid & $45.0^{\circ}$ & $20 \mathrm{R}_{\mathrm{n}}$ & $100 \%$ \\
$1 \mathrm{R}_{\mathrm{n}}$ & Round & $0.0^{\circ}$ & $20 \mathrm{R}_{\mathrm{n}}$ & $100 \%$ \\
$1 \mathrm{R}_{\mathrm{n}}$ & Round & $0.0^{\circ}$ & $15 \mathrm{R}_{\mathrm{n}}$ & $100 \%$ \\
$1 \mathrm{R}_{\mathrm{n}}$ & Round & $0.0^{\circ}$ & $20 \mathrm{R}_{\mathrm{n}}$ & $100 \%$ \\
Varied & Round & $0.0^{\circ}$ & $20 \mathrm{R}_{\mathrm{n}}$ & $70 \%$ \\
Varied & Round & $0.0^{\circ}$ & $20 \mathrm{R}_{\mathrm{n}}$ & $80 \%$ \\
Varied & Round & $0.0^{\circ}$ & $20 \mathrm{R}_{\mathrm{n}}$ & $90 \%$ \\
Varied & Round & $0.0^{\circ}$ & $20 \mathrm{R}_{\mathrm{n}}$ & $110 \%$ \\
Varied & Round & $0.0^{\circ}$ & $20 \mathrm{R}_{\mathrm{n}}$ & $120 \%$ \\
Varied & Round & $0.0^{\circ}$ & $20 \mathrm{R}_{\mathrm{n}}$ & $100 \%$ \\
\hline
\end{tabular}

\section{Assumptions for Ascent Stage Analysis}

The simulation of the ascent engine was performed with a combination of the Chemical Equilibrium Compositions (CEC) [15], Boundary Layer Integral Matrix Procedure (BLIMP) [16], and RAMP codes with the procedure documented in Reference [17]. The ascent engine was modeled with identical assumptions as the descent engine, but with a lower thrust. As mentioned previously, because of geometrical constraints, the inflow for the ascent stage DSMC solutions was near the nozzle exit plane leading to number densities well within the continuum regime. Therefore, a scaling factor of 100 was used to lower the density. The same scaling factor was used to scale up the applicable results. DSMC solutions were computed for three altitudes (ascent vehicle heights), each with different \pm pitch/yaw rotations of the ascent vehicle. Simulations were performed for nominal ascent launches (with the lunar surface included) and for abort scenarios (without the lunar surface). A single solution with no rotation and at the lowest altitude was computed for a "fire in the hole" scenario in which the plume gases are blocked and forced to vent in the opposite direction.

\section{SUMMARY OF RESULTS}

The results of the Altair Lunar Lander plume impingement analysis are summarized below. The plots presented are a sample of the total analysis performed. Both surface plots and flow field plots are shown where applicable.

Example plots from the descent stage analysis are shown in Figures 2 and 3. Figure 2 plots the number density for a center plane slice through the flow field. A strong bow shock is observed as well as some weaker shocks 
emanating from the craters on the left and right side of the plume centerline. Plots of the lunar surface pressure and shear can be seen in Figures 3(a) and 3(b), respectively. The flow field and surface properties obtained from this analysis were used in a separate study investigating lunar soil erosion and debris tracking [18] which was similar to the studies done before and after the Apollo landings [5].
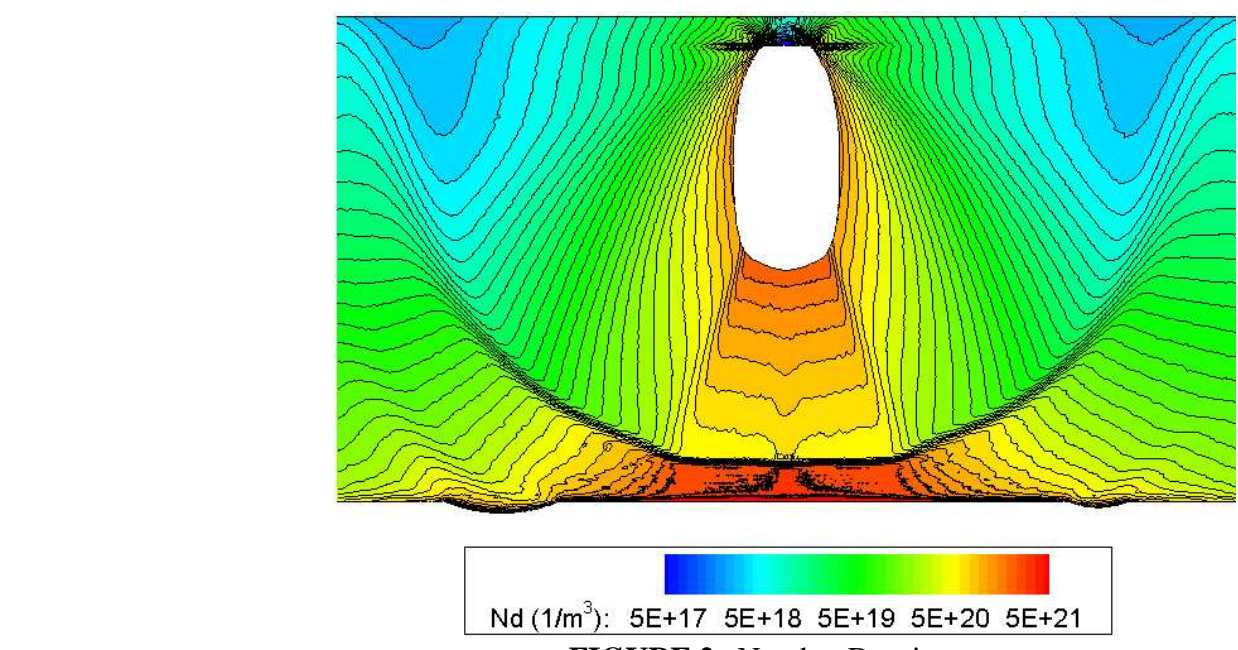

FIGURE 2. Number Density.

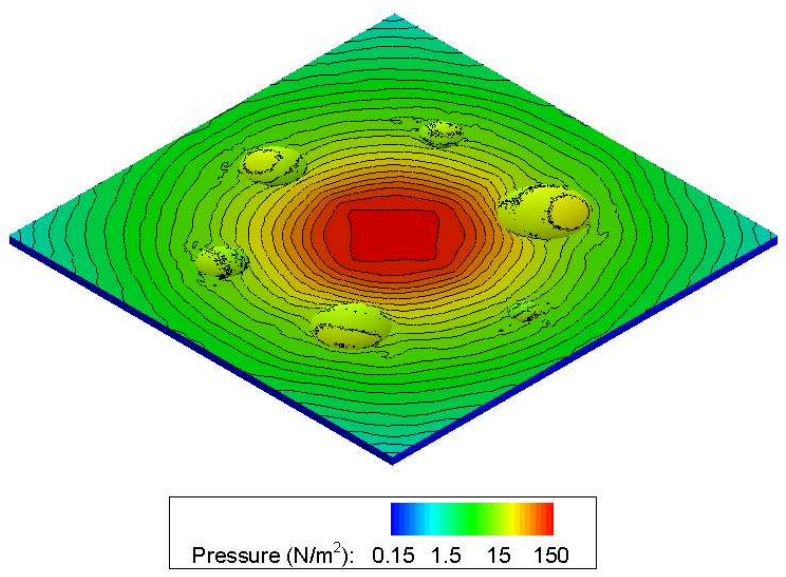

(a)

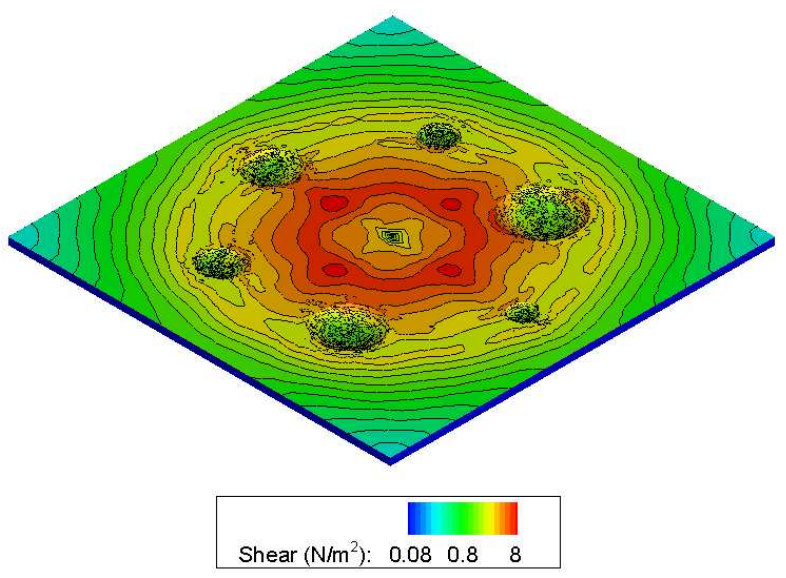

(b)

FIGURE 3. Surface plots of (a) Pressure and (b) Shear.

Example plots from the ascent stage plume impingement analysis are shown in Figure 4. The velocity flow field is shown in a center plane slice in Figure 4(a). This example plot of an abort scenario is for the lowest altitude case when the ascent stage engine nozzle is closest to the internal components of the descent stage vehicle. There is a small $-3^{\circ}$ rotation about the $\mathrm{Y}$-axis which causes the pressure distribution on the ascent vehicle to be highly asymmetric and moves the location of the maximum pressure in the $+Z$ direction. The pressure distributions on the ascent vehicle are shown in Figure 4(b). The asymmetry in the pressure distribution on the ascent vehicle causes moments about the Y-axis.

The ascent stage engine firing caused extremely high heating to the descent stage internal components. At the lowest altitude, the worst case heating computed was approximately $1300 \mathrm{~W} / \mathrm{cm}^{2}$, which drops quickly to around $600 \mathrm{~W} / \mathrm{cm}^{2}$ at the highest altitude simulated (difference of $1.62 \mathrm{~m}$ ).

\section{Scaling Study}

A scaling factor of 100 was used in the ascent stage plume impingement analysis in order to make the large number density more manageable in the DSMC solution. In order to understand the effect of the scaling factor on 
the final results, comparisons were made for a single case computed with scaling factors ranging from 20 to 200 . The total forces and moments on the ascent vehicle were computed for each scaling factor and are shown in Figure 5. It was observed that the total force (mainly in the X-direction) varied by less than $6 \%$, but the total moment (mainly about the $\mathrm{Y}$-axis), although small in magnitude, varied by almost $50 \%$ over the entire range of factors.

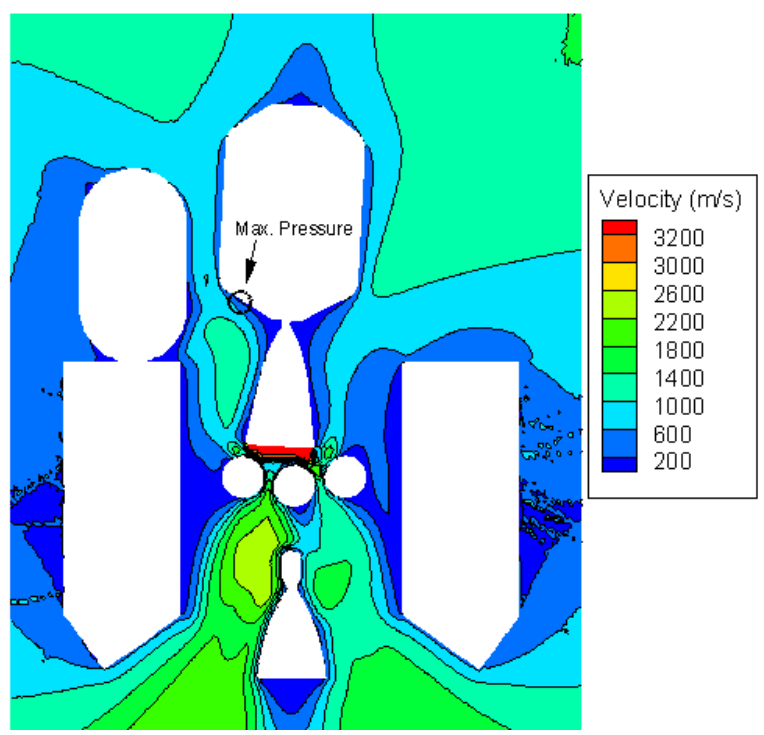

(a)

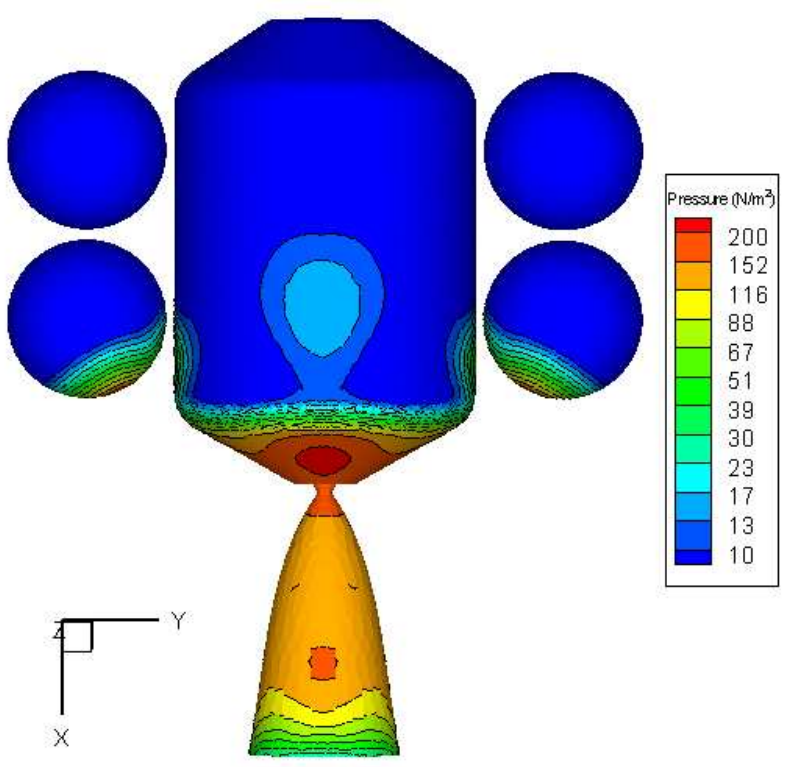

(b)

FIGURE 4. DSMC Solution showing (a) Velocity and (b) Pressure.

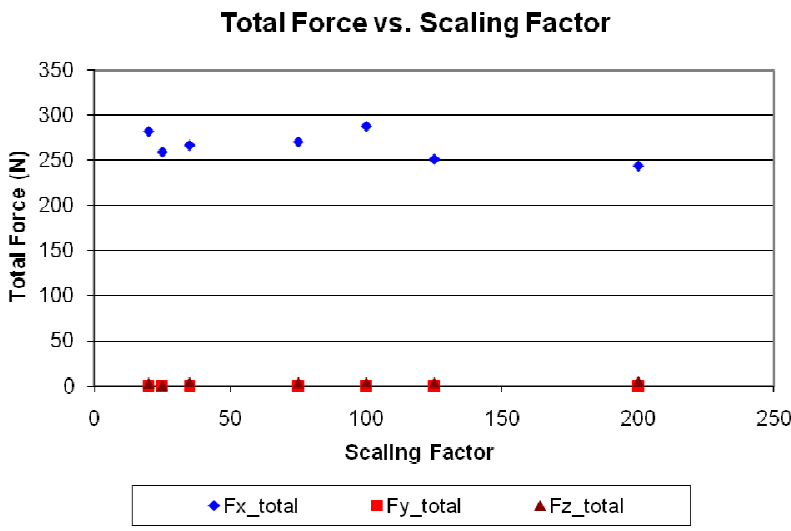

(a)

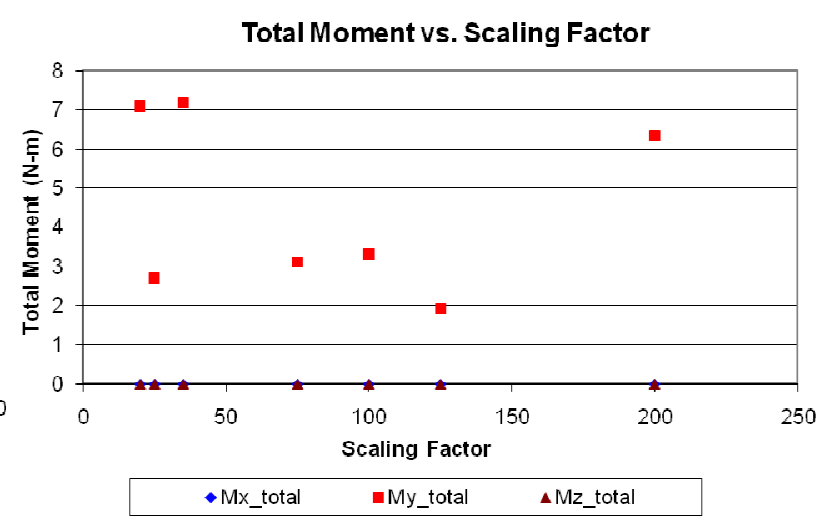

(b)

FIGURE 5. Effect of DSMC Solution Scaling on the Calculation of (a) Total Force and (b) Total Moment.

\section{Inflow Geometry Study}

The geometry of the inflow boundary was also varied in the ascent stage plume impingement analysis in order to gauge the effects on the final results. The original inflow surface used a flat plate inflow geometry, which was deemed inappropriate because the flow around the nozzle lip was not adequately captured. Two other inflow geometries - one with a circle radius and the other with sharp edge solid walls - were used in the analysis to account for flow around the nozzle lip and were compared to the RAMP solution, as shown in Figure 6. Although both of the alternate inflow geometries showed a similar comparison to the RAMP solution, the sharp edge, solid wall inflow geometry was recommended because it allows the inflow to be closer to the nozzle exit plane. This type of inflow geometry will be used for any future analyses where geometric constraints require the inflow boundary to be near the engine nozzle exit plane. 


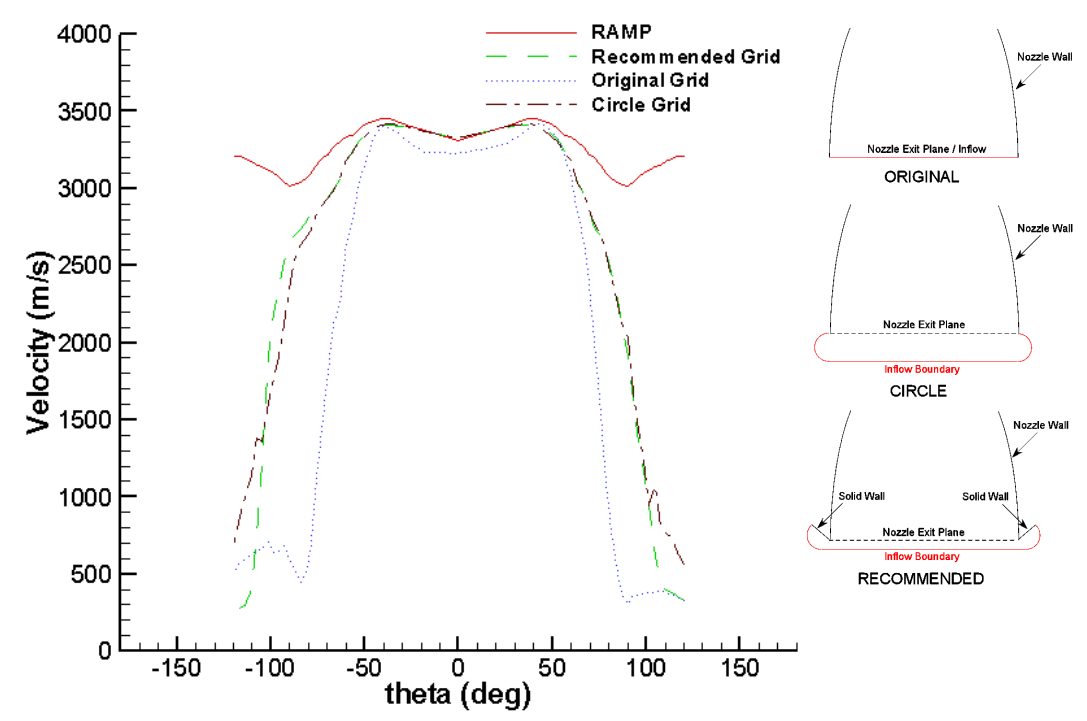

FIGURE 6. Effect of Inflow Geometry on Velocity.

\section{REFERENCES}

1. Crawford, D. R., "Application of the Monte Carlo Direct Simulation Technique to Rarefied Plumes and Plume Impingement,” TRW 70.4313.1-12, May 1970.

2. Lumpkin, F. E., III, LeBeau, G. J., and Stuart, P. C., “A CFD/DSMC Analysis of Plumes and Plume Impingement During Shuttle/Mir Docking," AIAA Paper No. 95-2034, 30th AIAA Thermophysics Conference, June 1995.

3. Lumpkin, F. E., III, LeBeau, G. J., and Stuart, P. C., "An Enhanced Analyses of Plume Impingement During Shuttle-Mir Docking Using a Combined CFD and DSMC Methodology," AIAA Paper No. 96-1877, 31st AIAA Thermophysics Conference, June 1996.

4. Rochelle, W. C., D' Attorre, L., and Hutton, R. E., “ Investigation of Lunar Module Plume Flow-Fields and Impingement Effects," Paper Presented at $6^{\text {th }}$ JANNAF Plume Technology Conference, Monterey, CA, Mar. 1971.

5. Roberts, L., "The Interaction of a Rocket Exhaust with the Lunar Surface," presented at the Specialists' Meeting on Fluid Dynamics Aspects of Space Flight, AGARD, Marseilles, France, April 20-24, 1964.

6. Hutton, R. E., "Lunar Surface Erosion During Apollo 11 Landing," TRW Systems Rpt. 11176-6068-R0-00, Nov. $20,1969$.

7. Hutton, R. E., "Descent Engine Plume Induced Surface Erosion During Apollo 11 and 12 Landings," TRW Systems 70.4340.4-8, 30 Mar. 1970.

8. Richardson, M. D., "Results of a Study of LM Ascent Motor Plume Impingement Forces and Pressures on ALSEP," LMSC/HREX D148775, April 1969.

9. Lumpkin, F. E., III, Boyles, K. A., and LeBeau, G. J., "Recent Advances in the High-Fidelity Simulation of Plume Impingement to Satellites," Paper Presented at $27^{\text {th }}$ JANNAF Exhaust Plume Technology Subcommittee Meeting, NASA Stennis Space Center, MS, May 8, 2003.

10. McGrory, W. D., Stack, D. C., Applebaum, M. P., and Walthers, R. W., "GASP Version 3.1 - The General Aerodynamic Simulation Program," AeroSoft, Inc., August 1997.

11. Bird, G. A., "Breakdown of Continuum Flow in Free Jets and Rocket Plumes," $12^{\text {th }}$ International Symposium on Rarefied Gas Dynamics, Progress in Aeronautics and Astronautics, 1981.

12. Smith, S. D., "Update to the RAMP2 Computer Program," SECA-FR-93-19, December 1993.

13. LeBeau, G. J. and Lumpkin, F. E., III, "Application Highlights of the DSMC Analysis Code (DAC) Software for Simulating Rarefied Flows," Computer Methods in Applied Mechanics and Engineering, 191, No. 6-7, 595-609 (2001).

14. LeBeau, G. J., Boyles, K. A., and Lumpkin, F. E., III, "Virtual Sub-Cells for the Direct Simulation Monte Carlo Method," AIAA Paper No.2003-1031, 41st AIAA Aerospace Sciences Meeting and Exhibit, Jan. 2003.

15. Gordon, S. and McBride, B. J., "Computer Program for Calculation of Complex Chemical Equilibrium Compositions, Rocket Performance, Incident and Reflected Shocks, and Chapman-Jouget Detonations," NASA SP-273, March 1976.

16. Evans, R. M. and Morse, H. L., "Boundary Layer Integral Matrix Procedure BLIMP-J User's Manual,” Aerotherm UM-7564, July 1975.

17. Kirk, B. S., Starbranch, E. S., and Rochelle, W. C., "Nozzle and Plume Flow-Field Analysis for ICM R6DM 5-lb Thrust Engine," Lockheed Martin Memo GN\&C 98-013, May 18, 1998.

18. Lane, J. E., Metzger, P. T., Immer, C. D., and Li, X., "Lagrangian Trajectory Modeling of Lunar Dust Particles," Earth \& Space 2008, Long Beach, CA, Mar. 3, 2008. 